\title{
Heavy Metal Concentrations in Street-Vended Fruits and Vegetables in Warri, Delta State, Nigeria
}

\section{OBI-IYEKE, GE}

\author{
Department of Botany, Delta State University, Abraka Nigeria.
}

. Email: ekyobiiyeke@gmail.com Tel:08034235271

\begin{abstract}
The concentration of metals ( $\mathrm{Pb}, \mathrm{Zn}, \mathrm{Cu}, \mathrm{Cr}, \mathrm{Cd}, \mathrm{Mn}$ and $\mathrm{Ni}$ ) in selected fruits and vegetables from Ekpan market in Warri Delta state, Nigeria were determined using Atomic Absorption Spectrometry (AAS). The concentrations of metals $(\mathrm{mg} / \mathrm{kg}$ ) in all samples ranged from ND-0.91, ND -1.12, 0.74-1.51, 0.27-1.83, 0.02-1.74 and 0.15 -1.93 for $\mathrm{Cd}, \mathrm{Cu}, \mathrm{Ni}, \mathrm{Mn}, \mathrm{Zn}$ and $\mathrm{Pb}$ respectively. $\mathrm{Cr}$ was not detected in all the samples. The result also indicated that the concentration of $\mathrm{Cd}, \mathrm{Cu}, \mathrm{Ni}, \mathrm{Mn}$ and $\mathrm{Zn}$ were within the permissible limit for WHO 2015 while the concentration of $\mathrm{Pb}$ in most samples were above the WHO 2015 limit hence pose toxicological risk. The study will bring awareness to consumers on the inherent health implication of food contamination with its attendant economic implication.
\end{abstract}

\section{DOI:https://dx.doi.org/10.4314/jasem.v23i3.12}

Copyright: Copyright $(92019$ Obi-Iyeke. This is an open access article distributed under the Creative Commons Attribution License (CCL), which permits unrestricted use, distribution, and reproduction in any medium, provided the original work is properly cited.

Dates: Received: 10 February 2019; Revised: 19 March 2019; Accepted 24 March 2019

Keywords: Contamination, Metals, Fruits; Vegetables

Toxicological and environmental studies have prompted interest in the determination of toxic elements in fruits and vegetables. Fruits and vegetables are an important part of a healthy diet and variety is as important as quantity. Therefore, fruits and vegetables are a very important class of food and are very useful for the maintenance of health and as preventive treatment of various diseases (D'Mello, 2003). Fruits and leafy vegetables are widely used for culinary purposes. They are used to increase the quality of soups (leafy vegetables) and also for their dietary purposes (Sobukola et al., 2010). They are made up of chiefly cellulose, hemi-cellulose and pectin that give them their texture and firmness (Sobukola et al., 2010).However, these food items are known to contain both essential and toxic metals over a wide range of concentrations. Heavy metals have been reported to have positive and negative roles in human life (Divrikli et al., 2003; Dundar and Saglam, 2004; Colak et al., 2005). Cadmium, lead and mercury are major contaminants of food supply and may be considered the most important problem to our environment while others like iron, zinc and copper are essential for biochemical reactions in the body (Zaidi et al., 2005). Fruits and vegetables are generally safe for dietary consumption but accumulation of their contaminants in the bodies of the consumers over a long period of time is of major concern as it can result to serious health conditions. Large amount of waste substances, effluents, chemicals and energy are introduced into the environment through several sources. Some of these substances contain heavy metals such as cadmium, lead, and mercury, which are known to be toxic to man and wildlife. Generally, most heavy metals are not biodegradable; they have long biological half-lives and have the potential for accumulation in the different body organs leading to unwanted side effects (Jarup, 2003; Sathawara et al., 2004). There is a strong association between micronutrient nutrition of plants, animals and humans and the uptake and impact of contaminants in these organisms (De Leonardis et al., 2000; Yuzbasi et al., 2003; Yaman et al., 2005). The content of essential elements in plants is conditional, the content being affected by the characteristics of the soil and the ability of plants to selectively accumulate some metals (Divrikli et al., 2006). In addition to the soil, other sources of heavy metals for plants are; Rainfall in atmospheric-polluted areas, traffic density, use of oil or fossil fuels for heating, atmospheric dusts, plant protection agents and fertilizers, which could be absorbed through aerial parts such as the fruits and leaves (Kovacheva et al., 2000; Lozak et al., 2002; Atrouse et al., 2004). These plant materials could also be contaminated by various substances including trace metals as farmers wash them with unhygienic water before bringing them into the market (Divrikli et al., 2006). Some of these elements are toxic to humans even at a very low level. Heavy metal contamination of food items is one of the most important considerations in food quality assurance (Marshall, 2004; Wang et al., 2005; Khan et al., 2008). Heavy 
metal contamination in vegetables cannot be underestimated as these food items are highly nutritious, largely consumed and form important components of human diet. International and national regulations on food quality have lowered the maximum permissible levels of toxic metals in food items due to an increased awareness of the risk, these metals pose to food chain contamination. Based on persistent nature and cumulative behavior as well as the probability of potential toxicity effects of heavy metals as a result of consumption of leafy vegetables and fruits, there is need to test and analyze these food items to ensure that the levels of these trace elements meet the agreed international requirements.

This study is particularly important for farm products from this part of the world where only limited data on heavy metal contents of such highly consumed agricultural produce are available. The study therefore sought to qualitatively and quantitatively establish possible heavy metal contamination of some streetvended fruits and vegetables in Warri, Delta state, Nigeria with a view to comparing the results with those available in the literature and the tolerable limits of WHO/FAO recommendations.

\section{MATERIALS AND METHOD}

Sample Collection: Two types of fruits garden egg (Solanum melongena), orange (Citrus sinensis) and two vegetables water leaf (Talinum fruticosum) and bitter leaf (Vernonia amygdalina) were purchased from the Ekpan market in Warri, Delta State. Ten samples were collected for each type given a total of forty samples. Samples were properly washed after the bruised and rotten parts were removed, labeled, kept in plastic bags and then refrigerated.

Sample preparation and treatment: Samples collected were processed on the same day. The fruits were rinsed with distilled water, peeled, sliced to obtain the edible portion for analysis. Vegetables were also rinsed with distilled water and cut to simulate human intake conditions. Samples for analysis were dried using the oven dry method at $105^{\circ} \mathrm{C}$ for $24 \mathrm{hrs}$; and processed for analysis by dry-ashing method. The dried samples were then powdered manually in a mixer grinder.

Powdered samples (14g each), with three Powdered replicates taken from each food item, were accurately weighed and placed each in a silica crucible, and few drops of concentrated nitric acid was added to aid ashing. The dry-ashing process was carried out in a muffle furnace by stepwise increase of the temperature up to $550^{\circ} \mathrm{C}$ and the samples left to ash at this temperature for $6 \mathrm{hrs}$. The ash was kept in desiccators and then rinsed with $3 \mathrm{M}$ hydrochloric acid. The ash suspension was filtered into a $50 \mathrm{~mL}$ volumetric flask through Whatman No. 1 filter paper, and the volume was made up to the mark with $3 \mathrm{~N}$ hydrochloric acid.

Qualitative analytical methods: In this study, the qualitative procedure adopted for the determination of heavy metals of interest in the selected fruits and vegetables made use of the Osumex's Heavy metal Test Kit. The kit contains a color chart for test results against which the presence of the metals, were detected or determined. The digested samples $(5 \mathrm{ml}$ of each) was taken into glass tube, exactly 2 drops of liquid reagent of the kit (containing complexes of cupferon solution, Potassium bromide, hydrazine solution, chloroform, Ammonium molybdate solution etc) was added to the samples. After a little while, there were different colour developments depending on each metal concentration in the samples.

Standards: Standard solutions of the heavy metals, namely, lead $(\mathrm{Pb})$, cadmium $(\mathrm{Cd})$, copper $(\mathrm{Cu})$, nickel $(\mathrm{Ni})$, and zinc $(\mathrm{Zn})$, were purchased from Merck (Darmstadt, Germany). The standards were prepared from the individual $1000 \mathrm{mg} / \mathrm{L}$ standards (Merck) supplied in $0.1 \mathrm{~N} \mathrm{HNO}_{3}$. A series of working standards were prepared from these standard stock solutions.

Quantitative analytical methods: Analysis of the heavy metals of interest was carried out using Atomic Absorption Spectrophotometer, RAYLEIGH WFX110B. Measurements were made using standard hollow cathode lamps for $\mathrm{Pb}, \mathrm{Cd}, \mathrm{Zn}, \mathrm{Cu}$, and $\mathrm{Ni}$. The limit of detection (LOD) of the analytical method for each metal was calculated as being triple the standard deviation of a series of measurements for each solution, the concentration of which is distinctly detectable above the background level. These values were $0.001,0.001,0.001,0.003$, and $0.002 \mathrm{mg} / \mathrm{kg}$ for $\mathrm{Pb}, \mathrm{Cd}, \mathrm{Zn}, \mathrm{Cu}$, and $\mathrm{Ni}$, respectively. Also, the limit of quantification (LOQ) of the element was determined; these were calculated as 0.003, 0.003, 0.003, 0.01, and $0.007 \mathrm{mg} / \mathrm{kg}$ for $\mathrm{Pb}, \mathrm{Cd}, \mathrm{Zn}, \mathrm{Cu}$, and $\mathrm{Ni}$, respectively.

Quality assurance: Appropriate quality assurance procedures and precautions were taken to ensure the reliability of the results. Samples were carefully handled to avoid cross-contamination. Glassware was properly cleaned, and reagents used were of analytical grades. De-ionized water was used throughout the study. Reagent blank determinations were used to apply corrections to the instrument readings. For validation of the analytical procedure, repeated analyses of the samples against internationally certified plant standard reference material (SRM) of the National Institute of Standard and Technology 
were used, and the results were found to lie within $\pm 1 \%$ of the certified values.

Statistical analyses: Two types of statistical analyses were carried out on the replicated values of the quantitative results using the computer-based SPSS (statistical) software version 17.0. Firstly, one-way analysis of variance was conducted along with Duncan's multiple range tests (at $\mathrm{P}=0.01$ ) to compare the means of each heavy metal across the six food items; and secondly, for each heavy metal, the mean for each food item was compared with the WHO/FAO permissible level as test value using a one-sample student t-test at $99 \%$ confidence interval of the difference.

\section{RESULT AND DISCUSSION}

The qualitative and quantitative results of heavy metals in the selected fruits and vegetables obtained in this study are as shown in Tables 1 to 3. Heavy metals have been widely acknowledged to adversely affect the nutritive values of agricultural produce on account of their deleterious effect on human beings. Therefore, national and international regulations on food quality have set the maximum permissible levels of toxic metals in human food. As such, an increasingly important aspect of food quality assurance has been to control the concentrations of heavy metals in food (Sobukola et al., 2010).It is gratifying to note that arsenic (Ar), chromium $(\mathrm{Cr})$ and mercury $(\mathrm{Hg})$ were not detected in these commonly consumed fruits and leafy vegetables (Table 1). These three are highly toxic heavy metals, their presence in foods should be very negligible or trace amount. Arsenic plays a role in the development of diabetes, cancer, vascular disease and lung disease (Jarup, 2003). Mercury is a global pollutant which comes from local industrial sources, such as smelters or coal-fired power plants. Some quantity also falls out of the atmosphere from distant polluters and there are natural sources, such as erupting volcanoes (Selin and Selin, 2006).Arising from this study, $\mathrm{Pb}$ was present in bitter leaf and water leaf and manganese (Mn) was detected in orange. In a similar study, Yuzbasi et al. (2003) detect Pb in water leaf, and this could be due to the way these vegetables are packaged in sacks, in such a way that they are ordinarily exposed to atmospheric contaminants. Moreover, it is likely that water leaf is a good candidate when it comes to phyto-extraction of $\mathrm{Pb}$ from soil (Yuzbasi et al., 2003; Mepha et al., 2007). In contrary, heavy concentrations of $\mathrm{Pb}$ were detected in the other food items studied (Table 2), and statistically speaking, the quantity of this serious cumulative body poison far surpasses the permissible level (Table 3).

Table 1. Qualitative results of heavy metals in some fruits and vegetables from Warri, delta state, Nigeria

\begin{tabular}{llllllll}
\hline & \multicolumn{7}{c}{ Heavy metals } \\
\cline { 2 - 7 } Fruit/Vegetables & $\mathrm{Pb}$ & $\mathrm{Cd}$ & $\mathrm{Cr}$ & $\mathrm{Zn}$ & $\mathrm{Cu}$ & $\mathrm{Mn}$ & $\mathrm{Ni}$ \\
\hline Garden egg & + & + & - & + & + & - & + \\
Orange & + & - & - & + & - & + & + \\
Water leaf & + & + & - & + & + & + & + \\
Bitter leaf & + & + & - & + & + & + & + \\
\hline \multicolumn{7}{c}{ Positive $(+)$ detected, Negative (-) not detected. }
\end{tabular}

Table 2. Means of heavy metal concentration $(\mathrm{mg} / \mathrm{kg})$ in some fruits and vegetables from Warri, Delta State, Nigeria.

\begin{tabular}{l|l|l|l|l}
\hline & \multicolumn{3}{|c}{ Fruit/ vegetable samples } \\
\hline Heavy metals & Garden egg & Orange & Water leaf & Bitter leaf \\
\hline $\mathrm{Pb}$ & 1.71 & 0.15 & 1.93 & 0.99 \\
$\mathrm{Zn}$ & 1.56 & 0.02 & 1.61 & 1.74 \\
$\mathrm{Cu}$ & 0.94 & $\mathrm{ND}$ & 1.07 & .12 \\
$\mathrm{Cr}$ & $\mathrm{ND}$ & $\mathrm{ND}$ & $\mathrm{ND}$ & $\mathrm{ND}$ \\
$\mathrm{Ni}$ & 1.02 & 0.74 & 1.51 & 0.96 \\
$\mathrm{Cd}$ & 0.91 & $\mathrm{ND}$ & 0.73 & 0.17 \\
$\mathrm{Mn}$ & 1.73 & 0.27 & 1.83 & 0.95 \\
\hline \multicolumn{4}{|c}{}
\end{tabular}

Table 3. Results of comparison of heavy metal concentration in some fruits and vegetables with W.H.O. /F.A.O. permissible values.

\begin{tabular}{l|l|l|l|l|l}
\hline & & \multicolumn{4}{|c}{ Fruit/ vegetable samples } \\
\hline Heavy metals & W.H.O (2015) & Garden egg & Orange & Water leaf & Bitter leaf \\
\hline $\mathrm{Pb}$ & 0.50 & 1.71 & 0.15 & 1.93 & 0.99 \\
$\mathrm{Zn}$ & 50.0 & 1.56 & 0.02 & 1.61 & 1.74 \\
$\mathrm{Cu}$ & 0.50 & 0.94 & $\mathrm{ND}$ & 1.07 & .12 \\
$\mathrm{Cr}$ & 0.50 & $\mathrm{ND}$ & $\mathrm{ND}$ & $\mathrm{ND}$ & $\mathrm{ND}$ \\
$\mathrm{Ni}$ & 1.02 & 0.74 & 1.51 & 0.96 \\
$\mathrm{Cd}$ & 0.50 & $\mathrm{ND}$ & 0.73 & 0.17 \\
$\mathrm{Mn}$ & 5.0 & 1.73 & 0.27 & 1.83 & 0.95 \\
\hline \multicolumn{5}{l}{}
\end{tabular}


These four food items were observed to accumulate $\mathrm{Pb}$ beyond tolerable limits for human consumption (Table 3). The high levels of $\mathrm{Pb}$ in these plants may probably be attributed to pollutants in irrigation water, farm soil or due to pollution from the highways traffic (Ladipo and Doherty, 2011). Lead is a serious cumulative body poison which enters into the body system through air, water and food and cannot be removed by washing fruits and vegetables (Divrikli et al., 2003).The concentration of cadmium $(\mathrm{Cd})$, zinc $(\mathrm{Zn})$, copper $(\mathrm{Cu})$, cobalt $(\mathrm{Co})$, manganese $(\mathrm{Mn})$ and nickel $(\mathrm{Ni})$ observed in the fruits and vegetables were substantially lower than the maximum permissible values (Table 3; WHO, 2015).

Conclusion: From the results obtained in this study, chromium which have been acknowledged as serious human poison were absent in most fruits and vegetable samples procured from Ekpan market in Warri Delta State in Nigeria. However, the concentration of lead in most fruits and vegetables were significantly higher than the maximum WHO/FAO permissible level thus posing a serious health risk. Regular monitoring is also required over long period as the vegetables are transported from different sources. Farmers should be educated to reduce such contamination by controlling the use of pesticide, herbicide, use of wastewater and encourage cultivating in field far from highway and industrial area.

\section{REFERENCES}

Atrouse, OM; Oran, SA; Al-Abbadi, S.Y (2004). Chemical analysis and identification of pollen grains from different Jordanian honey samples. Inter. J. Food Sci. Technol. 39: 413-417.

Colak, H; Soylak, M; Turkoglu, O (2005). Determination of trace metal content of herbal and fruit teas produced and marketed from Turkey. Trace Elements and Electrolytes 22: 192195.

D'Mello, JPF. (2003). Food Safety: Contaminants and Toxins, Scottish Agricultural College, Edinburgh, UK, 480 pages.

Divikli, U.; Horzum,N.;Soylak, M. and Elci, L (2006). Trace heavy metal contents of some spices and herbal plants from western Anatolia, Turkey. International Journal of Food Science and Technology 41: 712-716.

Divrikli, U.; Saracoglu, S.;Soylak, M. and Elci, L. (2003). Determination of trace heavy metal contents of green vegetables samples from
Kayseri-Turkey by flame atomic absorption spectrometry. Fresenius Environmental Bulletin 12: 1123-1125.s

Dundar, MS. and Saglam, HB (2004). Determination of Cadmium and Vanadium in Tea varieties and their infusions in comparison with two infusion processes. Trace Elements and Electrolytes 21: 60-63.

Jarup, L., (2003). Hazards of heavy metal contamination. Br. Med. Bull., 68:167-182.

Kovacheva, P.;Djingova, R; Kuleff, I. (2000). On the representative sampling of plants for multi element analysis. Photochemical Balance.6: 91102.

Ladipo, MK; Doherty,VF (2011). Heavy metal levels in vegetables from selected markets in Lagos, Nigeria. Afr. J. Food Sci. Technol. 2: 018-021.

Lozak, A., Soltyk, K., Ostapczuk, P. and Fijalek, Z. (2002). Determination of selected trace elements in herbs and their infusions. Sci. Total Environ. 289: 33-40.

Marshall, R (2004). Enhancing Food chain integrity: Quality assurance mechanism for air pollution impacts on fruits and vegetables systems Crop post-Harvest program, Final Technical Report (R7530).

Mepha, HD.; Eboh, L; Banigbo, DEB (2007). Effects of processing treatments on the Nutritive Composition and consumer acceptance of some Nigerian edible leafy vegetables. African Journal of Food Agric and Nutrition Development.7: 1-18

Sathawara,NG; Parikish, DJ; Agrwal, YK.( 2004). Essential heavy metals in environmental samples from western Indian. Bull. Environ. Contam. Toxicol. 73: 756-761.

Selin, NE;Selin, H(2006). Global Politics of Mercury Pollution: The Need for Multi-Scale Governance. RECIEL 15 (3): 258-268.

Sobukola, OP.; Adeniran, MO.; Odedairo, AA; Kajihausa, OE (2010). Heavy metal levels of some fruits and vegetables from selected markets in Lagos, Nigeria. African Journal of Food Science 4: 389-393. 
Wang, XT; Sato, YM; Xing, B; Tao, S. (2005). Health risks of Heavy metals to the general public in Tiajin, China via consumption of vegetables and fish. Sci. Total Environ. 330: 28-37.

WHO (2006). Guidelines for the safe use of waste water, excetera and grey water: Waste water use in agriculture (volume 2). Geneva, WHO, 2:219.

Yaman, M; Okumus N; Bakirdere S; Akdeniz, I. (2005). Zinc speciation in soils and relation with its concentration in fruits. Asian J. Chem. 17: 6672 .

Yuzbasi, N.; Sezgin, E; Yildirim, M; Yildirim, Z. (2003). Survey of lead, cadmium, iron, copper and zinc in Kasar cheese. Food Additive and Contamination. . 20: 464-469.

Zaidi, MI; Asrar, A; Mansoor A; Farooqui, MA (2005). The heavy metal concentrations along Road side trees of Quetta and its effects on public health. J. Appl. Sci. 5: 708-711 